\title{
EDITORIALS
}

\section{Thinking fast and slow in pneumonia}

See linked article by Lee et al. on pg 149

\section{Gopalakrishnan Netuveli ${ }^{1,2}$}

1 Professor of Public Health, Institute of Health and Human Development, University of East London

2 International Centre for Life Course Studies, University College London

*Correspondence: Professor Gopal Netuveli, Professor of Public Health, Institute for Health and Human Development, University of East London, Suite 250, University House, The Green, Water Lane, London E15 4LZ, UK

Tel: +44 (0)2082236342 Fax: +44 (0)208 2234282

E-mail: g.netuveli@uel.ac.uk

"In my opinion", Hippocrates starts his book on Prognostics, "it is highly necessary that a physician should bestow the utmost pains in attaining a foreknowledge of events, for when, with the sick, he perceives beforehand, and evinces a clear conception of the past, present, and future, discovering at the same time the neglects which they have committed, a higher degree of credit will be paid to his knowledge of their situation: so that mankind will, with greater confidence, commit themselves to his care. The cure will be better performed from a foreknowledge; but it is not possible that all the sick should be restored to a state of health, as the power of effecting this would indeed far surpass any anticipation of consequences." ${ }^{1}$

Thus did the father of Modern Medicine lay the foundation of the art of prognostication in medicine. It is a necessary skill for a physician, but also one with uncertainties attached to its outcomes. However, according to Christakis, it is a skill that has been omitted from modern medical thought due to the emergence of effective therapies and a fundamental shift in the conceptualisation of disease in terms of diagnoses rather than with reference to patients. ${ }^{2} \mathrm{He}$ added that prognosis became implicit in diagnosis and treatment, thus losing its explicit identity. Glare and Sinclair demonstrated quantitatively the subservience of 'prognosis' to 'diagnosis' and 'therapy' by measuring the number of hits in a PubMed search; the number of hits for prognosis was eight to nine times less than those for the other two terms. $^{3}$ To an extent, the disappearance of 'prognosis' could be ascribed to the fact that the term is mostly associated with an answer to the question "Doc, how much time do I have?" ${ }^{4}$ a question only one in three physicians discusses with their patients ${ }^{5}$ - and avoided because physicians find themselves ill-prepared for prognostication and find it stressful to make predictions. ${ }^{6}$ This digression into the 'lost art in M edicine ${ }^{\prime 7}$ is prompted by the paper by Lee et al. in this issue of the PCRJ, which compares rules for predicting the severity of hospitalised nursing home-acquired pneumonia in Korea. ${ }^{8}$

Pneumonia is on the top of the list of causes of death in older ages and demands considerable attention from healthcare professionals, especially as their resources become limited. In response to constraints, the care setting for pneumonia has changed; this in turn is reflected in the varieties of pneumonia which have been described, resulting in a veritable 'alphabet soup': CAP, HAP, HCAP, NHAP, and VAP. ${ }^{9}$ Community-acquired pneumonia (CAP) is distinct from other nosocomial forms of pneumonia like hospital-acquired pneumonia (HAP) and ventilator-associated pneumonia (VAP). ${ }^{10}$ However, it is used as a catch-all classification for pneumonia acquired in non-hospital settings even when they are associated with health care. In 2005, the American Thoracic Society/Infectious Disease Society Guidelines designated pneumonia acquired in health care settings (like nursing homes and long-term care facilities) as health care-associated pneumonia (HCAP). ${ }^{11} \mathrm{~A}$ sub-group of HCAP was further distinguished as nursing home-acquired pneumonia (NHAP).

The uses of a prediction tool in pneumonia include informing the physician about the management of the patient in terms of 'when', 'where' and 'how' - and, less commonly, informing the patient and/or family about the likely outcome. There are more such tools for CAP than NHAP, which would have been one of the motivations for Lee et al. to embark on their study. They pitted an NHAP-specific model against the Pneumonia Severity Index (PSI), SOAR (systolic blood pressure, oxygenation, age, and respiratory rate) and CURB-65 (confusion, urea nitrogen, respiratory rate, blood pressure, and age $>65$ ), and found that PSI had the greatest power of discrimination in predicting 30-day all cause mortality.

Interestingly, in the original study where it was introduced, PSI did not predict mortality and was proposed as a prediction rule to identify low risk patients. ${ }^{12}$ In Lee et al.'s paper, PSI had a sensitivity of 78.3 and a specificity of 66.7 , both below the 80 mark usually suggested as desirable for both sensitivity and specificity. Given such uncertainties, should such a mechanistic prediction rule guide the physician and supplant the art of prognostication with a machine? Although no head-to-head comparison between human and statistical prediction in respiratory diseases has been done, in mental health this has been a hotly discussed topic since 1954, when Paul Meehl, a Psychology professor, published his book comparing clinical versus statistical prediction. ${ }^{13}$ M eehl presented 20 studies, the oldest from 1928, where clinical and statistical predictions were compared, and demonstrated the superiority of statistical prediction - much to the consternation of the profession. More recent reviews, using meta-analytical techniques, have continued to confirm these initial findings. Meehl's work influenced the Nobel prize-winning economist Daniel Kahneman, who in his latest book (whence the title of this editorial) highlights the 
varieties of cognitive illusions that can hamper human judgement. ${ }^{14} \mathrm{~A}$ prediction rule has no such illusions.

Conflicts of interest GN is the Statistical editor of the PCRJ, but was not involved in the editorial review of, nor the decision to publish, this article.

Commissioned article; not externally peer-reviewed; accepted 7th May 2013; online 24th May 2013

(c) 2013 Primary Care Respiratory Society UK. All rights reserved http://dx.doi.org/10.4104/pcrj.2013.00051

Prim Care Respir J 2013; 22(2): 139-140

\section{References}

1. Hippocrates. The Prognostics And Prorrhetics Of Hippocrates (Translated by Moffat J). Riverside, CA: Ulan Press 2012 p1.

2. Chistakis NA. The ellipsis of prognosis in modern medical thought. Soc Sci Med 1997;44:301-15. http://dx.doi.org/10.1016/S0277-9536(96)00100-1

3. Glare PA, Sinclair CT. Prognostication. J Palliative Med 2008;11:84-103. http://dx.doi.org/10.1089/jpm.2008.9992

4. Loprinzi CL, Johnson ME, Steer G. Doc, how much time do I have? J Clin Oncol 2000;18:699-701

5. White DB, Engelberg RA, Wenrich MD, Lo B, Curtis JR. Prognostication during physician-family discussions about limiting life support in intensive care units. Crit Care Med 2007;35:442-8

http://dx.doi.org/10.1097/01.CCM.0000254723.28270.14
6.

Christakis NA, Iwashyna AB. Attitudes and self-reported practice regarding prognostication in a national sample of Internists. Arch Intern Med 1998; 158 2389-95. http://dx.doi.org/10.1001/archinte.158.21.2389

7. Jones CA. Prognostication: Medicine's lost art. Medicine \& Health 2008;91:347-8.

8. Lee J-C, Hwang H-J, Park Y-H, Joe J-H, Chung J-H. Comparison of severity predictive rules for hospitalised nursing home-acquired pneumonia in Korea. Prim Care Respir J 2013;22(2):149-54. http://dx.doi.org/10.4104/pcrj.2013.00011

9. Anand N, Kollef MH. The Alphabet Soup of Pneumonia: CAP,HAP, HCAP, NHAP, and VAP. Seminars in Respiratory and Critical Care Medicine 2009;30:3-9. http://dx.doi.org/10.1055/s-0028-1119803

10. Kollef, MH, Shorr A, Tabak, YP, et al. Epidemiology and outcomes of healthcare-associated pneumonia: results from a large US database of culture-positive pneumonia. Chest 2005;128:3854-62. http://dx.doi.org/10.1378/chest.128. 6.3854

11. American Thoracic Society; Infectious Diseases Society. Guidelines for the management of adults with hospital-acquired,ventilator-associated, and healthcare-associated pneumonia. Am J Respir Crit Care Med 2005;171:388-416. http://dx.doi.org/10.1164/rccm.200405-644ST

12. Fine MJ, Auble TE, Yealy DM, et al. A prediction rule to identify low-risk patients with community-acquired pneumonia. N Engl J Med 1997;336:243-50. http://dx.doi.org/10.1056/NEJM199701233360402

13. Meehl P. Clinical versus statistical prediction: A theoretical analysis and a review of the evidence. Minneapolis: University of Minnesota Press 1954 http://dx.doi.org/10.1037/11281-000

14. Kahneman D. Thinking, fast and slow. London: Penguin 2011.

\section{Is once enough? Understanding the preferences of COPD and asthma patients for once- versus twice-daily treatment}

\section{See linked article by Price et al. on pg 161}

\section{*Rob Horne' \\ 1 Professor of Behavioural Medicine; UCL Academic Lead, Centre for the Advancement of Sustainable Medical Innovation (CASMI); Director, Centre for Behavioural Medicine, UCL School of Pharmacy, University College London, London, UK}

*Correspondence: Professor Rob Horne, UCL School of Pharmacy, Mezzanine Floor, BMA House, Tavistock Square, London WC1H 9JP, UK

Tel: +44 (0)20 78741281 Fax: +44 (0)20 738756932

E-mail: r.horne@ucl.ac.uk

Once-daily treatments are sometimes perceived to be the 'holy grail' in terms of promoting adherence. The idea that a simple once a day administration regime will foster adherence is certainly beguiling, but the research evidence is more nuanced. A number of systematic review $\mathrm{S}^{1,2}$ and a recent meta-analysis ${ }^{3}$ have addressed the relationship between adherence and dose frequency, and their findings do indeed suggest an inverse gradient between dose frequency and adherence. The meta-analysis by Coleman and colleagues $^{3}$ was methodologically more advanced and focused on oral dosage forms where adherence was assessed by electronic monitoring. The overall finding was that patients with long-term conditions (including three studies of patients with asthma) are more adherent to once-daily oral regimes than more frequent dosing and adherence was significantly higher for once- versus twice-daily regimes. This contrasts with the Claxton ${ }^{1}$ and Saini ${ }^{2}$ reviews which found that once-daily treatment was associated with significantly higher adherence than treatment three or four times a day, but found no significant differences between once- and twice-daily regimes overall.

However, we should be cautious about extrapolating these findings to a prescription of once-daily maintenance therapy for all patients with asthma and COPD. Although the aforementioned reviews ${ }^{1-3}$ are well designed, they are inevitably limited by the fact that they draw on heterogeneous studies. Moreover, differences in adherence between once- versus twice-daily regimes, although statistically significant in the Coleman review, ${ }^{3}$ were relatively small; the percentage of doses taken was $93.0 \%(95 \% \mathrm{Cl} 91.2$ to $94.7 \%)$ versus $85.6 \%(95 \% \mathrm{Cl} 82.5$ to $88.8 \%)$, respectively. These findings are similar to those obtained by Price and colleagues in their 12-week open-label study of 1,233 patients with asthma randomised to receive once-daily versus twice-daily dosing of mometasone fumarate administered by dry powder inhaler; ${ }^{4}$ adherence was significantly higher with once-daily dosing, but adherence was high across the study and the difference between the dosing regimens was small $(93.3 \%$ vs. $89.5 \%)$ - indicating that twice-daily dosing was not a significant barrier for most patients in the study. Nevertheless, research to date seems to be consistent with the 2008 UK National Institute for Health and Clinical Excellence (NICE) M edicines Adherence Guidelines 